\title{
Food protein-induced enterocolitis syndrome - a review of the literature with focus on clinical management
}

\author{
Marine Michelet ${ }^{1, *}$ \\ Dominique Schluckebier ${ }^{2, *}$ \\ Laetitia-Marie Petit ${ }^{2}$ \\ Jean-Christoph Caubet ${ }^{3}$ \\ 'Children Hospital, Pediatric \\ Allergology Unit CHU Toulouse, \\ Toulouse, France; ${ }^{2}$ Geneva University \\ Hospitals, Pediatric Gastroenterology \\ Unit, ${ }^{3}$ Geneva University Hospitals, \\ Pediatric Allergology Unit, Geneva, \\ Switzerland \\ *These authors contributed equally to \\ this work
}

This article was published in the following Dove Press journal:

Journal of Asthma and Allergy

27 June 2017

Number of times this article has been viewed

\begin{abstract}
Food protein-induced enterocolitis syndrome (FPIES) is a potentially severe presentation of non-IgE-mediated gastrointestinal food allergy (non-IgE-GI-FA) with heterogeneous clinical manifestations. Acute FPIES is typically characterized by profuse vomiting and lethargy, occurring classically 1-4 hours after ingestion of the offending food. When continuously exposed to the incriminated food, a chronic form has been described with persistent vomiting, diarrhea, and/or failure to thrive. Although affecting mainly infants, FPIES has also been described in adults. Although FPIES is actually one of the most actively studied non-IgE-GI-FAs, epidemiologic data are lacking, and estimation of the prevalence is based on a limited number of prospective studies. The exact pathomechanisms of FPIES remain not well defined, but recent data suggest involvement of neutrophils and mast cells, in addition to $T$ cells. There is a wide range of food allergens that can cause FPIES with some geographical variations. The most frequently incriminated foods are cow milk, soy, and grains in Europe and USA. Furthermore, FPIES can be induced by foods usually considered as hypoallergenic, such as chicken, potatoes or rice. The diagnosis relies currently on typical clinical manifestations, resolving after the elimination of the offending food from the infant's/child's diet and/or an oral food challenge (OFC). The prognosis is usually favorable, with the vast majority of the case resolving before 5 years of age. Usually, assessment of tolerance acquisition by OFC is proposed every 12-18 months. Of note, a switch to an IgE-mediated FA is possible and has been suggested to be associated with a more severe phenotype. Avoiding the offending food requires education of the family of the affected child. A multidisciplinary approach including ideally allergists, gastroenterologists, dieticians, specialized nurses, and caregivers is often useful to optimize the management of these patients, that might be difficult.
\end{abstract}

Keywords: FPIES, FPIES management, FPIES diagnosis, non-IgE-mediated gastrointestinal food allergy, cow milk

\section{Introduction}

Food protein-induced enterocolitis syndrome (FPIES) is a severe presentation of nonIgE-mediated food allergy affecting the gastrointestinal (GI) tract mainly in infants and young children. ${ }^{1,2}$ This syndrome is typically characterized by profuse vomiting and lethargy, occurring classically 1-4 hours after ingestion of the offending food. ${ }^{3}$ Diagnosis of FPIES is difficult, and misdiagnosis is common. ${ }^{4,5}$ There are a number of differential diagnosis that should be ruled out. Thus, FPIES is often confounded with sepsis, metabolic diseases, severe gastroenteritis, or even abdominal surgical
Correspondence: Jean-Christoph Caubet Geneva University Hospitals, Pediatric Allergology Unit, 6 Rue Willy Donzé, 1205 Geneva, Switzerland Email jean-christoph.caubet@hcuge.ch 
emergencies before reaching a final diagnosis. ${ }^{6}$ Recent studies have suggested that FPIES is not as rare as previously believed. ${ }^{4,6-8}$ But despite increased interest, our understanding of its pathomechanism remains limited, and many management aspects are still highly debated, including emerging recommendations regarding the introduction of new foods in FPIES patients and follow-up.

In this review we will discuss the epidemiology, clinical characteristics, incriminated foods, pathomechanisms, diagnosis, and differential diagnosis of FPIES, with a particular focus on management aspects.

\section{Epidemiology}

Although FPIES was initially described in the 1940s, a limited number of studies have been published until the recent surge in interest. ${ }^{9}$ Currently, FPIES is one of the most actively studied non-IgE-mediated GI food allergies (non-IgE-GIFAs). ${ }^{10}$ Epidemiologic data are lacking, and estimation of the prevalence is based on a limited number of prospective studies. ${ }^{7,11}$ Thus, a prospective birth cohort study conducted over 2 years in Israel reports a $0.34 \%$ prevalence of FPIES to cow's milk (CM) and $0.5 \%$ IgE-mediated FA to CM in the same study cohort. ${ }^{7}$ These results were quite surprising, as the prevalence of FPIES was believed to be much lower than the one of IgE-mediated allergy. Another prospective study cohort conducted through a national register in Australia showed an incidence of 1/10,000 cases per year including all different food triggers. ${ }^{11}$ However, this lower incidence is likely to be underestimated due to methodological issues. ${ }^{5}$

FPIES can present at all ages, with a slight male predominance. ${ }^{5}$ In contrast to eosinophilic esophagitis, there is no strong familial association in both parents and siblings. ${ }^{12,13}$ However, association with atopic diseases is commonly reported, particularly atopic dermatitis (up to $57 \%$ ). ${ }^{14,15}$ Other atopic diseases such as allergic rhinitis, asthma, IgE-mediated FA, and eosinophilic esophagitis or gastroenteritis might also be infrequently associated. ${ }^{4,12,16} \mathrm{Katz}$ et al, observed that infants with CM-FPIES were more often delivered by c-section, suggesting a role for intestinal microbiota in the development of FPIES. ${ }^{7}$ However, these data have not been confirmed afterwards.

Further epidemiologic data are needed in the future, not only to have an accurate estimate of the prevalence in different countries, but also to identify risk factors to develop FPIES.

\section{Clinical manifestations}

FPIES is classical described as chronic or acute. ${ }^{17,18}$ In the chronic form, as initially described by Powell, patients typi- cally present with chronic intermittent emesis, diarrhea with blood or mucus, abdominal distension, and/or lethargy. In the most severe cases patients progress to dehydration, metabolic abnormalities, nutritional deficiencies, and failure to thrive (FTT). In some cases, even older children can present with chronic FPIES in case of frequent repetitive solid food ingestion. ${ }^{19}$ However, chronic FPIES remains not well defined and due to its aspecific clinical symptoms, the diagnosis is often difficult, particularly as symptoms may overlap with other non-IgE-GI-FAs mediated allergy (food protein-induced enteropathy [FPE] and food protein-induced allergic proctocolitis [FPIAP]). In addition, the literature regarding this disorder is poor and most of the currently published studies did not include a confirmatory oral food challenge (OFC). Moreover, some authors have been speculated that chronic FPIES might be a separate disease entirely, not just a different presentation. ${ }^{20}$

Acute FPIES is typically characterized by repetitive profuse vomiting $(90 \%-100 \%)$, pallor $(14 \%-67 \%)$, and/ or lethargy (3\%-85\%), typically occurring $1-4$ hours after ingestion of the offending food. ${ }^{2,10}$ Diarrhea may follow $5-10$ hours later, in up to $50 \%$ of infants and in only $30 \%$ of children older than 1 year of age. , $^{2,7,10}$ Hypotension in FPIES has been reported in up to $15 \%$ of patients in some series. ${ }^{7,10,12,16}$ Of note, acute FPIES can be the initial presentation or may occur after a period of exclusion in patients with chronic FPIES after reintroduction of the offending food (acute-on-chronic form). In the vast majority of cases, the first reaction appears after the first or second ingestion of the causative food. ${ }^{4}$ Although chronic form of FPIES may occur in breastfed infants, the acute form has been rarely described in exclusively breastfed infants. 5,6

The age at presentation for the acute form is variable and may depend on the offending food. Thus, it has been shown that FPIES to solids typically appears later than FPIES to CM or soy, probably owing to the timing of solid foods introduction into the diet. ${ }^{2,12}$ But other factors (i.e., environmental and genetic) probably influence the development of FPIES. Adult onset FPIES to fish and/or shellfish is an example of FPIES, probably unrelated to delayed food introduction. ${ }^{12,21}$

\section{Pathophysiology}

FPIES is typically classified as a non-IgE-GI-FA, but its exact pathomechanisms remain not well defined.

Several studies have suggested a key role for $T$ cells in FPIES patients, particularly by founding positive patch test or positive lymphocyte transformation test to the specific 
food allergen..$^{22-28}$ It has been suggested that secretion of proinflammatory cytokines TNF- $\alpha$ and IFN- $\gamma$, in combination with a relative lack of expression of TGF- $\beta$-receptors (known as a protector of the intestinal wall) may contribute to local inflammation and increased intestinal permeability. ${ }^{16,29-31}$ Nevertheless, it has been shown that neither peripheral blood mononuclear cell proliferation nor patch tests can be used as a diagnostic tool at an individual level, questioning the role of $\mathrm{T}$ cell in FPIES patients. ${ }^{22-26,29}$ The role of these cells has been further challenged by recent data showing similar CD4+ $\mathrm{T}$ cell-proliferative responses after casein stimulation in $\mathrm{CM}$ FPIES patients to those with IgE-mediated CM allergy and those tolerating $\mathrm{CM}^{32}$

The mechanism of tolerance acquisition in FPIES remains unclear. CD4+CD25+ regulatory $\mathrm{T}$ cells might be implicated, as they have been increasingly identified in infants/children who acquired tolerance to the incriminated food. ${ }^{33}$ It is hypothesized that they exert a suppressive action via cell to cell contact and by the production of TGF- $\beta$ and IL-10. ${ }^{26,33}$ Recently, data support the suggested key role of IL-10 in acquisition of tolerance in patients with $\mathrm{CM}$ FPIES. ${ }^{32}$

The role of neutrophils has also been discussed, as they typically increase after ingestion of the incriminated food, peaking at 6 hours. ${ }^{18}$ In addition, neutrophils have been found in gastric aspirate and stool mucus in patients with FPIES, as well as in biopsies from FPIES patients. An increase of serum IL-8 levels after positive OFC also suggested a key role of these cells. ${ }^{32}$ However, their role in the pathomechanism of FPIES has not been clearly demonstrated; the rise in peripheral neutrophil count could simply reflect unspecific stress response or the side effect of steroid administration as treatment. ${ }^{1,4,17,18,34}$ From another point of view, eosinophils have been found in biopsies from FPIES patients, suggesting a potential involvement of these cells. ${ }^{35,36}$ Recently, a potential role of mast cells has been suggested, but these data need to be confirmed by further studies. ${ }^{32}$

Although FPIES is typically categorized as a non-IgE mediated allergic disorder, some FPIES patients may have positive specific IgE to the causal protein either at onset or during follow-up; this is referred to as "atypical FPIES". ${ }^{12,19,37}$ Of note, a switch from the non-IgE to an IgE phenotype, or the opposite is possible, and the relation between non-IgE-GI-FA and IgE-mediated FA required further investigation. ${ }^{2,33,37}$

The observed increase of specific IgA and IgG antibodies in patients with FPIES has raised the question of a humoral response in this disorder. ${ }^{24,34,38}$ However, recent study suggests that their role is probably limited. ${ }^{32}$

Further studies are needed to better understand the pathomechanism of this disease. Recent pathological findings are summarized in Table 1.

\section{Offending foods}

There is a wide range of food allergens that can cause FPIES. In Europe and USA, the most frequently incriminated foods are CM, soy, and grains..$^{5-8,15,16,20,39-41}$ Furthermore, FPIES can be induced by foods usually considered as hypoallergenic, such as meat, white and sweet potatoes, chicken, mushrooms, fruits and vegetables. ${ }^{2-4,6,15,16,19,20,39-47}$ There are some geographical variations regarding the frequency of incriminated foods in FPIES that are summarized in Table 2. These differences may be related to country-specific food habits, in particular differences in the timing of food-introduction in infancy. ${ }^{2,20,48}$ Thus, FPIES to CM and soy commonly appear in the first 3 months of life. It has been recently suggested that early introduction of $\mathrm{CM}$ or soy formula is a risk factor for the development of CM or soy FPIES, respectively. ${ }^{2}$ American infants have a lower rate of breastfeeding and are earlier exposed to formula CM than Australian infants. ${ }^{5}$ In Australia and Europe soy formula is rarely used in the first 24 months of life, whereas soy formula is frequently used in the USA even before 6 months of life. ${ }^{11,49}$ This might explain, at least partially, the relatively high prevalence of FPIES to soy in USA compared to other countries. In Australia chicken is one of the first solid foods introduced in the child's diet,

Table I Summary of our current understanding of the pathophysiology of FPIES

- A central role of T cells in the local intestinal inflammation has been suggested, but still need to be confirmed

- A deficit in TGF- $\beta$ I response and overzealous TNF- $\alpha$ response may be important factors in FPIES

- IL-I0 might play a key role in acquisition of tolerance in patients with FPIES

- Increased serum IL-8 levels in patients with active FPIES suggest neutrophils involvement

- A potential role of IL-9 in the pathogenesis of FPIES has been recently suggested, potentially through its influence on intestinal permeability

- Elevated baseline serum tryptase levels have been found in patients with active FPIES suggest low-grade intestinal

- Mast cell activation or increased mast cell load

- Paucity of humoral response in FPIES has been suggested in several studies

Although several immune changes have been shown in FPIES patients, the pathophysiology of the disease remains not well defined and requires further characterization

Abbreviation: FPIES, food protein-induced enterocolitis syndrome. 
Table 2 Distribution of offending food for FPIES in different countries

\begin{tabular}{|c|c|c|c|c|c|c|c|c|c|c|c|c|}
\hline Year & Country & $\begin{array}{l}\text { Total no } \\
\text { of cases }\end{array}$ & $\begin{array}{l}\text { Cow } \\
\text { milk }\end{array}$ & Soy & Grains & Fish & Poultry & Vegetables & Fruits & Other & Comment & References \\
\hline 1998 & USA & 16 & II & 11 & 0 & 0 & 1 & & & & 7 patients to both & 1 \\
\hline \multirow[t]{2}{*}{2003} & USA & 14 & 5 & 8 & $90,10 \mathrm{R}$ & 0 & 1 & & & 3 & II $(78 \%)>$ I food & 12 \\
\hline & & & & & $2 \mathrm{~B}$ & & & & & & $9(64 \%)$ also soy + CM & \\
\hline 2003 & Israel & 6 & 3 & 2 & 0 & 0 & 4 & & & 2 & & 39 \\
\hline 2005 & Spain & 14 & & & & 14 & & & & & I patient with lgE & 40 \\
\hline 2009 & Korea & 23 & 11 & 12 & I R & I & 0 & & & I & & 8 \\
\hline \multirow[t]{2}{*}{2009} & Australia & 31 & 7 & 10 & I4 R, I O & I & I & & & 1 & $36 \%$ avec R-FPIES & 15 \\
\hline & & & & & & & & & & & reaction to other foods & \\
\hline 2011 & Israel & 44 & 44 & & & & & & & & & 7 \\
\hline \multirow[t]{2}{*}{2012} & Italy & 66 & 44 & 3 & $3 R$ & 8 & 2 & & & 5 & $56(85 \%)$ react to only & 6 \\
\hline & & & & & I C & & & & & & I food & \\
\hline \multirow[t]{2}{*}{2013} & USA & 462 & 309 & 189 & $88 \mathrm{R}, 74 \mathrm{O}, 46$ & 4 & 21 & 50 & 45 & 81 & $70 \%$ react to $I-2$ foods & 14 \\
\hline & & & & & $W, 18 B, 37 \mathrm{C}$ & & & & & & & \\
\hline 2013 & Australia & 4 & & & Egg & None & & & & & & 41 \\
\hline
\end{tabular}

Abbreviations: B, barley; C, corn; CM, cow milk; FPIES, food protein-induced enterocolitis syndrome; O, oat; R, rice; W, wheat.

which might explain why FPIES to chicken appears earlier in Australia compared to USA where only $28 \%$ of the children under 6 months have tried chicken. . $^{11,50}$

Most children react to a single food (i.e., $65 \%-80 \%$ ). ${ }^{10}$ Nevertheless, FPIES to multiple foods is not uncommon and the prevalence seems to vary geographically. ${ }^{4,6,7}$ Thus, it has been shown that a significant proportion of infants with FPIES to CM or soy (i.e., 37\%-50\%) will also react to soy or CM respectively, as well as to other foods (19\%). ${ }^{8,20,23,51}$ However, these associations have not been found in other studies. ${ }^{4,6,7}$ FPIES to multiple solid foods has also been particularly described in infants with FPIES to grains. ${ }^{2,14}$ Indeed, infants with FPIES to grains such as rice, oat, or barley are particularly at risk of developing FPIES to other grains. ${ }^{2,20}$ In American studies, it has been shown that concomitant FPIES to oat and rice can occur in up to $35-44 \%$ of patients with FPIES to oat or rice. ${ }^{2,14}$ However, the proportion of FPIES to multiple solid foods was significantly lower in studies outside USA. Higher proportion of patients reacting to multiple foods in USA might also be explained by inclusion of more severe cases recruited in tertiary centers, compared to studies from Israel, Italy or Australia. In addition, the pathophysiology, heritability and molecular mechanisms of co-allergies remain unclear and furthers studies are needed. FPIES to fish is mainly described in older children and adults, and is relatively common in Italy and Spain. ${ }^{40,52}$ Of note, in most of the cases $(65 \%)$ children react to one single fish. ${ }^{52}$

\section{Diagnosis}

Diagnosis of FPIES may be difficult, particularly due to the lack of specific biomarkers to confirm or exclude the diagnosis. Indeed, FPIES is a clinical diagnosis, mainly based on typical clinical manifestations, after exclusion of other causes. Currently, there are no fully validated diagnostic criteria for FPIES. The different proposed diagnostic criteria are detailed in Table 3. The more recent diagnostic criteria have been adapted from the initial criteria proposed in 1978 by Powell, to include the acute phenotype of FPIES. ${ }^{18}$ Basically, the infant/child should present with typical digestive symptoms that resolve after avoidance of the incriminated food. The reexposition to the incriminated should lead to reappearance of clinical signs. Symptoms must be limited to the digestive tract and IgE-mediated symptoms should be excluded. ${ }^{53}$

A positive OFC has been part of diagnostic criteria for a long time. However, in clinical practice a confirmatory OFC is not performed in children with several clear FPIES reactions. In fact, at the present time, common practice is to diagnose FPIES without confirmatory OFC in patients experiencing 2 or more typical episodes. ${ }^{6}$ When OFC is performed, the interpretation is usually based on Powell's diagnostic criteria. ${ }^{54} \mathrm{~A}$ revision of these criteria has also been proposed, which focus on clinical aspects (especially vomiting) and blood testing (leukocytosis) over stool analysis. ${ }^{55}$ Indeed, diarrhea is present only in a small proportion of patients, and stool analyses are not routinely performed in most reference centers.

Of note, an OFC should always be performed in an appropriate setting, particularly with a trained team and emergency drugs available. ${ }^{55,56} \mathrm{~A}$ peripheral intravenous (PIV) line is historically recommended, but its utility remains debated, particularly in patients with mild initial reaction. ${ }^{757,58}$ Although 
Table 3 Diagnostic criteria FPIES

\begin{tabular}{|c|c|c|c|}
\hline Powell ${ }^{18}$ & Powell $^{54}$ & Leonard and Nowak-Wegrzyn ${ }^{53}$ & Miceli Sopo et al $^{74}$ \\
\hline $\begin{array}{l}\text { Onset of symptoms at } \\
<2 \text { months of age } \\
\text { Infants }<9 \text { months of age at } \\
\text { study time }\end{array}$ & $\begin{array}{l}\text { Disappearance of symptoms } \\
\text { (vomiting and diarrhea) and of } \\
\text { diagnostic findings in the stool } \\
\text { (blood and leukocytes) after all } \mathrm{Ag} \\
\text { are removed from the diet }\end{array}$ & $\begin{array}{l}\text { Less than } 9 \text { months of age at initial } \\
\text { diagnosis }\end{array}$ & $\begin{array}{l}\text { Less than } 2 \text { years of age at first } \\
\text { presentation (frequent feature but } \\
\text { not mandatory) }\end{array}$ \\
\hline $\begin{array}{l}\text { While receiving the } \\
\text { offending food (formula) the } \\
\text { infant has watery } \\
\text { stools with mucus, blood } \\
\text { and leukocytes, and a } \\
\text { peripheral PNL }\end{array}$ & $\begin{array}{l}\text { No other cause for colitis } \\
\text { detectable }\end{array}$ & $\begin{array}{l}\text { Repeated exposure to causative food } \\
\text { elicits gastrointestinal symptoms } \\
\text { without alternative cause }\end{array}$ & $\begin{array}{l}\text { Exposure to the incriminated food } \\
\text { elicits repetitive and projectile } \\
\text { vomiting, pallor, lethargy within } \\
2-4 \text { hours. Diarrhea may be present, } \\
\text { much less frequently and later. } \\
\text { The symptoms last a few hours, } \\
\text { usually resolve within } 6 \text { hours }\end{array}$ \\
\hline $\begin{array}{l}\text { Diarrhea ceases and } \\
\text { normal growth resumes } \\
\text { when the offending food } \mathrm{Ag} \\
\text { is eliminated }\end{array}$ & $\begin{array}{l}\text { Symptoms do not recur and weight } \\
\text { gain is normal for I month on a } \\
\text { low } \mathrm{Ag} \text { formula as the only dietary } \\
\text { source }\end{array}$ & $\begin{array}{l}\text { Absence of symptoms that may } \\
\text { suggest an lgE-mediated reaction }\end{array}$ & $\begin{array}{l}\text { Absence of symptoms that may } \\
\text { suggest an IgE-mediated reaction }\end{array}$ \\
\hline \multirow[t]{2}{*}{$\begin{array}{l}\text { The response to challenge } \\
\text { meets the criteria of OFC }\end{array}$} & $\begin{array}{l}\text { Challenge with } \mathrm{CM} \text { or soy formula } \\
\text { or other offending food } \mathrm{Ag} \\
\text { reproduces symptoms of vomiting } \\
\text { within } 1-3 \text { hours and or diarrhea } \\
\text { within 4-10 hours }\end{array}$ & $\begin{array}{l}\text { Removal of causative food results in } \\
\text { resolution of symptoms }\end{array}$ & $\begin{array}{l}\text { Avoidance of the offending protein } \\
\text { from the diet results in resolution of } \\
\text { symptoms }\end{array}$ \\
\hline & & $\begin{array}{l}\text { Reexposure or OFC elicits typical } \\
\text { symptoms within } 4 \text { hours }\end{array}$ & $\begin{array}{l}\text { Reexposure or OFC elicits typical } \\
\text { symptoms within } 2-4 \text { hours } \\
\text { Two typical episodes are needed to } \\
\text { establish the diagnosis without the } \\
\text { need to perform OFC }\end{array}$ \\
\hline
\end{tabular}

Note: Reproduced from Serafini S, Bergmann MM, Nowak-Węgrzyn A, Eigenmann PA, Caubet JC. A case of food protein-induced enterocolitis syndrome to mushrooms challenging currently used diagnostic criteria. J Allergy Clin Immunol Pract. 2015;3(I):135-137.75

Abbreviations: Ag, antigen; CM, cow milk; FPIES; food protein-induced enterocolitis syndrome; PNL, polymorphonuclear leukocytosis; OFC, oral food challenge.

it has been found that up to $15 \%$ of patients developed hypotension, ${ }^{10}$ the majority of studies were performed in tertiary allergic medical centers, treating potentially more complex and severe cases. In comparison, Katz et al, treated successfully 28 reactions during OFC with simple oral rehydration, without any case of hypotension reported. ${ }^{7,57}$ The need for PIV access should be therefore carefully evaluated and let to the physician evaluation.

To date, there is no consensus on the optimal protocols for OFC in FPIES patients. Recommendations vary between the administration of one (full) single dose up to 3 increasing portions $(0.06-0.6 \mathrm{~g} / \mathrm{kg}) .^{20} \mathrm{~A}$ lower dose should be considered in patients who presented with a severe initial reaction. Skin prick and/or specific IgE measurement are recommended before performing OFC because of the potential risk of an IgE-mediated allergy. ${ }^{48}$ In case of IgE mediated FA, the OFC protocol should be adapted to an IgE-mediated allergy protocol. ${ }^{1,48}$

Some authors have found positive patch tests to the specific food antigen. ${ }^{21-27,31}$ Nevertheless, others have shown that patch tests have a poor predictive value (75\%) and could be falsely negative in up to $45 \%$ in patients with FPIES. Thus, they are not routinely recommended. ${ }^{11,22-29}$ Similarly, measurements of $\operatorname{IgG}$ and $\mathrm{IgG} 4$ antibodies in blood are not recommended. It is important to note that because diagnostic criteria focus on systemic impairment, local intestinal evaluation via endoscopy, and histological findings in FPIES remains poorly characterized. Although not recommended for routine diagnosis, endoscopy might be helpful in cases of unclear diagnosis to help rule out other conditions. In addition for research purposes, studies assessing macroscopic or histological changes in FPIES would be very useful. ${ }^{59}$

\section{Differential diagnosis}

As clinical features of FPIES are rather nonspecific, the differential diagnosis is extensive as shown in Table 4. Mehr et al, reported that a diagnosis is established in only $11 \%$ of patients presenting with an isolated acute episode, whereas the rest received no diagnosis or a misdiagnosis, such as viral infection or sepsis. ${ }^{5,56}$

Acute FPIES symptoms are very similar to infectious disease. ${ }^{4,54}$ Viral gastroenteritis is often suspected during the first episode. Hypotension and lethargy in infant can falsely lead to a diagnosis of sepsis. ${ }^{60}$ In the presence of hypotension, anaphylaxis is more often suspected than FPIES. In severe cases, FPIES can mimic an acute surgical abdomen. ${ }^{61}$ Of note, 
Table 4 Clinical features of FPIES and its differential diagnosis

\begin{tabular}{|c|c|}
\hline Clinical features & Differential diagnosis \\
\hline Signs and symptoms & Infections \\
\hline $\begin{array}{l}\text { Repetitive vomiting every } 10 \text { to } 15 \text { minutes, onset I-3 hours after } \\
\text { ingestion }(>90 \%)\end{array}$ & Viral gastroenteritis Sepsis \\
\hline Diarrhea, onset 5 hours after ingestion $(<50 \%)$ & Bacterial enteritis (Salmonella, Shigella, Campylobacter, Yersinia) \\
\hline Lethargy $(70 \%)$ & Parasites \\
\hline \multicolumn{2}{|l|}{ Pallor (70\%) } \\
\hline Dehydration & Allergic disorders \\
\hline Hypotension (15\%) & Other gastrointestinal non-lgE mediated food allergy disorders (food \\
\hline Hypothermia (25\%) & protein-induced enteropathy and eosinophilic gastrointestinal disorders) \\
\hline Abdominal distension & Acute IgE mediated allergy (anaphylaxis) \\
\hline Laboratory findings & Gastrointestinal disorders \\
\hline Elevated neutrophil count & Gastroesophageal reflux disease \\
\hline Thrombocytosis & Hirschsprung disease \\
\hline Metabolic acidosis & Intussusception \\
\hline Methemoglobinemia & Volvulus \\
\hline Fecal leukocytes and eosinophils & Pyloric stenosis \\
\hline Frank or occult fecal blood & Celiac disease \\
\hline \multicolumn{2}{|l|}{ Increased carbohydrate content in stool } \\
\hline Elevated gastric juice leukocytes & Other \\
\hline \multirow[t]{2}{*}{ Negative lgE test to the trigger food in most cases } & Neurologic disorders (i.e., seizure, encephalopathy, or bleeding) \\
\hline & $\begin{array}{l}\text { Heart defects (i.e., congenital heart disease, cardiomyopathy, or } \\
\text { arrhythmia) }\end{array}$ \\
\hline Radiologic features & Necrotizing enterocolitis \\
\hline Intramural gas & Congenital methemoglobinemia \\
\hline \multirow[t]{2}{*}{ Air-fluid levels } & Intoxication \\
\hline & Metabolic disorders, that is, hypoglycemia, MCAD deficit, biotinidase \\
\hline
\end{tabular}

Note: Reproduced from Barasche J, Stollar F, Bergmann MM, Caubet JC. Severely altered-consciousness status and profuse vomiting in infants: Food Protein-Induced Enterocolitis Syndrome (FPIES) a challenging diagnosis. Pediatr Emerg Care. Epub 2016 Oct $6 .^{76}$ http://journals.Iww.com/pec-online/pages/default.aspx. Promotional and commercial use of the material in print, digital or mobile device format is prohibited without the permission from the publisher Wolters Kluwer. Please contact healthpermissions@wolterskluwer.com for further information.

Abbreviations: FPIES, food protein-induced enterocolitis syndrome; MCAD, medium-chain-Acyl-CoA-dehydrogenase.

although specific blood tests are not necessary for FPIES diagnosis, they might be needed to eliminate sepsis, a metabolic disorder or a congenital methemoglobinemia for example.

Regarding the chronic form of FPIES, congenital mucosa abnormalities or necrotizing enteropathy could present with similar symptoms, and need to be ruled out in neonates and especially in preterm children. The chronic form of FPIES is clinically close to other food allergies such as celiac disease, FP or FPIAP. ${ }^{10}$ FPIAP appears often in exclusively breastfed and well-being infants in the first month of life, with isolated bloody stools. In this case, anemia can be the characteristic laboratory finding. FPE is characterized by inflammation localized in the small bowel causing malabsorption, leading to diarrhea, intermittent emesis and/or FTT. In most cases, FPIAP and FPE occur after ingestion of CM or soy formula. ${ }^{62}$ Moreover, primary eosinophilic GI disorders (EGIDs) may present with a phenotypic overlap. In addition, histological findings in EGIDs are also characterized by eosinophilic and mast cell infiltration. Thus, distinction between these disorders might be difficult in clinical practice, and from a physiopathological point of view, it is not clear if they are distinct disorders and if they are part of continuum.

\section{Natural history}

FPIES appears most frequently in the first months of life but can manifest at any age. ${ }^{2,42}$ FPIES to CM or soy begins in early infancy from several days to 4 weeks after the introduction of infant formula. In an Israeli population-based birth cohort the median onset of CM-induced FPIES onset was 30 days and all patients presented before 6 months. ${ }^{20}$ In breastfed infants the delay of onset seems to be longer. FPIES to solid-food usually begins in older infants because of later introduction into the diet, in general after 4 months of age. ${ }^{2,14}$

FPIES resolves at different ages according to the food involved and the population. ${ }^{6}$ Thus, in an American study CM-FPIES resolved in $20 \%$ of cases by 3 years of age, while a Korean cohort showed $>60 \%$ resolution by 10 months of age, and an Israeli birth cohort showed $90 \%$ resolution by the age of 30 months. ${ }^{2,7,8}$ Similar rates were found for soy FPIES in the American cohort with $20 \%$ of resolution by 
3 years of age, and again $90 \%$ of the Korean children showing resolution by 10 months of age. ${ }^{8}$ Those differences are probably explained by inclusion of different phenotype in the different studies, that is, more severe cases in American studies based on tertiary center. The natural history of FPIES to solid foods is less known and data are sparse. It has been found that $65.5 \%$ of children reactive to grains resolved their FPIES by 5 years of age, whereas those children who reacted to meat and fish/shellfish took more time: $50 \%$ and $0 \%$ at 5 years of age, respectively. ${ }^{2}$ FPIES to seafood seems to last longer than for other solids. ${ }^{12,50,63}$ Of note, it has been suggested that patients with atypical FPIES (i.e., with positive food-specific IgE to the incriminated food) appear to have a more protracted course. ${ }^{2,12}$

\section{Management}

The management of FPIES is still controversial in many aspects and mostly empiric, but the international guidelines are due out soon (Nowak-Wegrzyn et al, JACI, in press). In general, management of these patients has to include acute phase treatment as well as maintenance therapy in order to avoid recurrence of acute relapse, but also prevention of nutritional deficiencies. ${ }^{3,12,29}$

\section{Acute management}

\section{Supportive therapy}

Fluid repletion is the first line and the cornerstone of management. As acute FPIES mostly occurs at home, acute management starts there via oral hydration. Medical management is essential either in an outpatient clinic or in hospital to discuss intravenous volume repletion with normal saline bolus (20 $\mathrm{mL} / \mathrm{kg}$, that should be repeated if needed). Amines supportive therapy will be rarely needed, as the evolution is in most case quickly favorable after rehydration. Of note, although the use of epinephrine may be indicated to treat hypotension, it has no effect on preventing emesis. ${ }^{10,42}$

\section{Steroids therapy}

As local inflammation is suggested to be part of the pathophysiology of FPIES, a single dose of intravenous (IV) methylprednisone Solumedrol ${ }^{\circledR}(1-2 \mathrm{mg} / \mathrm{kg}$ up to $60-80 \mathrm{mg})$ in case of severe reactions may be considered. ${ }^{10}$ It can also play a role in the volume supportive therapy. But the utility of corticosteroids in FPIES has not been clearly demonstrated.

\section{Ondansetron}

Based on small case series reporting effectiveness of ondansetron injection during acute FPIES, its administration may be considered. ${ }^{64-66}$ Ondansetron, a 5- $\mathrm{HT}_{3}$ receptor antagonist has antiserotoninergic effect, that may play a role in gut secretion and motility via the afferent nerves. ${ }^{62,65,66}$ Ondansetron seems not only to reduce or prohibit nausea and vomiting, but also the development of diarrhea. ${ }^{62,65,66}$ The recommended dose ranges from 0.1 to $0.15 \mathrm{mg} / \mathrm{kg}$ administered IV or intramuscular (maximum single dose $16 \mathrm{mg}$ ) and is generally well tolerated. Sublingual administration can also be discussed. Nevertheless, contraindications (i.e., prolonged QT-interval and arrhythmia) exist ${ }^{10}$ and further large prospective and multicentric studies confirming its efficacy and safety are needed.

\section{Maintenance therapy}

After review of the acute episode, an emergency treatment letter including teaching of clinical features and management of acute FPIES episode should be provided to the parents/patient and can be shown in case of emergency to the physician. Indeed, formal education of the parents and, if appropriate, the child or adolescent is very important in order to avoid misdiagnosis of future episodes.

Maintenance therapy should include discussion of the following key points:

\section{Elimination of the offending food protein}

The diet until reintroduction under medical supervision is the rule. Avoidance of products with precautionary labeling (e.g., "can contain traces of", "run the same line") is usually not necessary. ${ }^{67}$ The success of the avoidance diet will also depend on whether they have seen a dietitian with experience in dealing with FPIES or not, as well as commercial availability of food, parental resources, cooking skills in the family, the number of allergens to avoid and/or the period of avoidance required. ${ }^{3}$ Indeed, these infants/children may benefit from nutritional evaluation and guidance, but also from laboratory assessment of iron, calcium, and vitamin D status. Supplementation may be then indicated and prescribed to these patients. Future studies should systematically evaluate the prevalence of feeding difficulties, poor weight gain, and growth and nutrient deficiencies for preventive intervention in this at-risk population. Of note, growth monitoring of those patients is particularly important.

\section{Breastfeeding}

The majority of infants with FPIES tolerate the incriminated allergen through breastfeeding without the need for a maternal eviction diet. ${ }^{20,68}$ Therefore, breastfeeding should be encouraged and routine avoidance of allergenic food is not recommended in breastfeeding mothers. ${ }^{3}$ Regarding patients 
with persistent symptoms, particularly FTT, empiric eviction of allergens by the mother might be indicated. ${ }^{69}$ The ideal length of the eviction trial is not known, probably several days up to 4 weeks appear sufficient. ${ }^{70}$

\section{The choice of formula}

The recommendations about formula in young infants with FPIES to CM who cannot be breastfed vary. While the guidelines from the World Allergy Organization recommend the use of an extensively hydrolyzed formula (EHF), the European society of pediatric gastroenterology, hepatology, and nutrition advise amino acid-based formula (AAF) for infants with FPIES, especially those with FTT, as AAF may confer advantages for catch up growth. ${ }^{3,70,71}$ Of note, it has been shown that $\sim 10 \%-20 \%$ of FPIES patients will require an $\mathrm{AAF}^{2,20}$ A reasonable approach would be to initiate treatment with EHF, and in those patients who do not display satisfactory symptom relief or catch up growth within 2 weeks, it would be necessary to switch to AAF. ${ }^{2,20}$ For patients with severe FPIES an AAF might be the optimal initial choice. As the palatability of the EHF formula is different, infants and children may decrease their daily volume of intakes and can be at risk for deficiency of calcium and other minerals and vitamins. This requires follow-up and supplementation in case of deficiency. ${ }^{72}$

\section{Heated or baked food proteins}

Current recommendations suggest avoiding all forms of the offending allergen, including baked and processed food. Indeed, there is only one report suggesting tolerance of small amount of the cooked offending food. ${ }^{72}$ But the introduction of baked foods under medical observation might be discussed if the family is interested, particularly baked egg or milk in patients with FPIES to egg or milk, respectively.

\section{Timing and setting of reintroduction of the offending food}

The actual recommendation based on US and Western Europe approach is an OFC 12-18 months after the last reaction. However, as previously discussed, the natural history of FPIES varies according the food incriminated, the population studied and probably the severity of the initial reaction. Thus, the decision to attempt reintroduction in order to assess tolerance acquisition should take all these factors into account. Shorter intervals might be adequate for patients with milder forms and those reacting to $\mathrm{CM}$ or soy, while longer intervals may be needed for patients with more severe form and those reacting to solids. However, further well-designed studies are needed to determine the optimal timing of OFC to assess tolerance acquisition.

General nutritional recommendations for infants and children with different types of FPIES are described in the following sections. ${ }^{73}$

\section{In infants with CM FPIES}

Avoidance of soy formula is usually recommended during the first months of life because of possible co-allergies with varying frequency in different countries. ${ }^{2,10,14,74} \mathrm{~A}$ reasonable approach would be to propose an OFC after 6 months to assess tolerance of soymilk formula in those patients. In patients with CM FPIES, the risk to develop FPIES to solids exists, and it is usually recommend to start between 6 and 12 months of age with yellow fruits or vegetables unlikely to cause FPIES, followed by meats and cereal grains. ${ }^{10}$ As there is a risk of successive FPIES on solid food, the introduction of solids known to cause solid FPIES such as grains, rice, and fish should be initiated with caution. It can be performed in a medical facility (particularly for severe CM FPIES) or at home at the discretion of the treating physician and with the supervision of a dietician who can support the whole weaning process and avoid unnecessary restriction. We recommend the introduction of one food per week. Introduction of any other animal milk, especially goat or sheep milk, is not recommended due to a higher risk of cross reactivity proteins. ${ }^{30,77}$

\section{Infants with soy FPIES}

Like infants with CM FPIES, infants with soy FPIES are at risk to react to $\mathrm{CM}$ formula as well as to solid foods, known to cause FPIES. Therefore, the recommendations are similar to those for infants with CM FPIES.

\section{Solid FPIES}

Infants/children with grains FPIES: Children with FPIES to rice, oat, barley or wheat are at risk to present symptoms after the ingestion of other grains. ${ }^{2,20}$ Because of their vulnerability, these patients might benefit from delayed introduction of grains beyond the first year of life. Introduction should be conducted under medical observation. CM and soy, if not already part of the child's diet, should be introduced after 6 months of age and under medical observation as co-allergies have been reported. The ingestion of all food already introduced and not responsive of the symptoms should be continued.

Infants/children with fish and/or shellfish FPIES: FPIES to fish follows the same guidelines than others solid food 
FPIES but with some specificities. It is a common solidfood FPIES in Italy and Spain. ${ }^{52}$ Similarly to IgE-mediated fish or shellfish allergy, as there are potential co-reactions with other fishes or shellfish, respectively, an OFC should be performed to assess tolerance. Of note, there is little data on resolution of FPIES to fish and seafood in older children and adults, and reintroduction should be considered in these patients, with a longer delay than for patients with FPIES to $\mathrm{CM}$ or soy.

\section{Conclusion}

FPIES is a non-IgE-GI-FA with heterogeneous features and is not a rarity in infants and children. It can potentially present with severe reactions requiring cautious management in short and long term. Diagnosis relies on medical history and typical symptoms like vomiting, pallor, lethargy, and diarrhea resolving after the elimination of the offending food from the infant's/child's diet and might relapse after OFC. The natural history is usually good in the vast majority of the case, supporting the reevaluation by OFC every $12-18$ months. But the possible switch to IgE-FA seems to predispose to a more prolonged phenotype.

Avoiding the offending food requires education of the family for the exposed patient. Because of the possible prolonged evolution before and after diagnosis, a multidisciplinary approach is required between allergists, gastroenterologists and dieticians, specialized nurses, and caregivers. Although some new recommendations have emerged those past years, new international guidelines are currently needed to improve the management of those patients. ${ }^{73}$

\section{Acknowledgment}

The authors thank Dr Valérie McLin for her critical review of the manuscript and English-language editing.

\section{Disclosure}

The authors report no conflicts of interest in this work.

\section{References}

1. Sicherer S, Burks AW, Sampson HA. Clinical features of acute allergic reactions to peanut and tree nuts in children. Pediatrics. 1998;102(1):e6.

2. Caubet JC, Ford LS, Sickles L, et al. Clinical features and resolution of food protein-induced enterocolitis syndrome: 10-year experience. J Allergy Clin Immunol. 2014;134(2):382-389.

3. Venter C, Groetch M. Nutritonal management of food protein-induced enterocolitis syndrome. Curr Opin Allergy Clin Immunol. 2014;14(3): 255-262.

4. Mehr S, Kakakios AM, Frith K, Kemp AS. Food protein-induced enterocolitis syndrome: 16-year experience. Pediatrics. 2009;123(3):459-464.

5. Mehr S, Frith K, Campbell DE. Epidemiology of food protein induced enterocolitis syndrome. Curr Opin Allergy Clin Immunol. 2014; 14(3):208-216.
6. Miceli Sopo S, Giorgo V, Iacono I, Novembre E, Mori F, Onesimo R. A multicenter retrospective study of 66 Italian children with food proteininduced enterocolitis syndrome: different management for different phenotypes. Clin Exp Allergy. 2012;42(8):1257-1265.

7. Katz Y, Goldberg MR, Rajuan N, Cohen A, Leshno M. The prevalence and natural course of food protein-induced enterocolitis syndrome to cow's milk: a large-scale, prospective population-based study. J Allergy Clin Immunol. 2011;127(3):647-653.

8. Hwang J, Sohn SM, Kim A. Prospective follow-up oral food challenge in food protein-induced enterocolitis syndrome. Arch Dis Child. 2009;94(6):425-428.

9. Rubin MI. Allergic intestinal bleeding in the newborn: a clinical syndrome. Med Sci. 1940;200:385-390.

10. Nowak-Węgrzyn A, Katz Y, Mehr SS, Koletzko S. Non-IgE-mediated gastrointestinal food allergy. J Allergy Clin Immunol. 2015; 135(5):1114-1124.

11. Garcia MR, Jimenez Diaz F. Food protein-induced enterocolitis syndrome (FPIES): our experience. J Allergy Clin Immunol. 2012; 129(2):AB34.

12. Nowak-Wegrzyn A, Sampson HA, Wood R, Sicherer S. Food proteininduced enterocolitis syndrome caused by solid food proteins. Pediatrics. 2003;111(4):829-835.

13. Shoda T, Isozaki A, Kawano Y. Food protein-induced gastrointestinal syndromes in identical fraternal twins. Allergol Int. 2011;60(1):103-108.

14. Ruffner M, Ruymann K, Barni S, Cianferoni A, Brwon-Whitehorn T, Spergel J. Food protein-induced enterocolitis- syndrome: insights from review of a large referral population. J Allergy Clin Immunol. 2013;1(4):343-349.

15. Mehr S, Kakakios AM, Kemp AS. Rice: a common and severe cause of food protein-induced enterocolitis syndrome. Arch Dis Child. 2009;94(3):220-223.

16. Sicherer S, Eigenmann PA, Sampson HA. Clinical features of food protein-induced enterocolitis syndrome. J Pediatr. 1998;133(2):214-219.

17. Powell GK. Enterocolitis in low-birth-weight infants associated with milk and soy protein intolerance. J Pediatr. 1976;88(5):840-844.

18. Powell GK. Milk- and soy-induced enterocolitis of infancy. Clinical features and standardization of challenge. J Pediatr. 1978;93(4):553-560.

19. Sicherer SH. Food protein-induced enterocolitis syndrome: case presentations and management lessons. J Allergy Clin Immunol. 2005;115(1):149-156.

20. Katz Y, Goldberg MR. Natural history of food protein-induced enterocolitis syndrome. Curr Opin Allergy Clin Immunol. 2014;14(3):229-239.

21. Tan JA, Smith WB. Non-IgE-mediated gastrointestinal food hypersensitivity syndrome in adults. J Allergy Clin Immunol Pract. 2014;2(3):355-357.

22. Van Sickle G, Powell GK, McDonald P, Goldblum R. Milk- and soy protein-induced enterocolitis: evidence for lymphocyte sensitization to specific food proteins. Gastroenterology. 1985;88(6):1915-1921.

23. Fogg MI, Brown-Whitehorn TA, Pawlowski NA, Spergel JM. Atopy patch test for the diagnosis of food protein-induced enterocolitis syndrome. Pediatr Allergy Immunol. 2006;17(5):351-355.

24. Shek LP, Bardina L, Castro R, Sampson HA, Beyer K. Humoral and cellular responses to cow milk proteins in patients with milkinduced IgE-mediated and non-IgE-mediated disorders. Allergy. 2005;60(7):912-919.

25. Benlounes N, Dupont C, Candalh C, et al. The threshold for immune cell reactivity to milk antigens decreases in cow's milk allergy with intestinal symptoms. J Allergy Clin Immunol. 1996;98(4):781-789.

26. Karlsson M, Rugtveit J, Brandtzaeg P. Allergen-responsive CD4+CD25+ regulatory T cells in children who have outgrown cow's milk allergy. $J$ Exp Med. 2004;199(12):1679-1688.

27. Hoffman KM, Ho DG, Sampson HA. Evaluation of the usefulness of lymphocyte proliferation assays in the diagnosis of allergy to cow's milk. J Allergy Clin Immunol. 1997;99(3):360-366.

28. Scarparrotta A, Di Pillo S, Consilvio NP, et al. Usefulness of Atopy Patch Test on a child with milk protein-induced enterocolitis syndrome: a case report. Int J Immunopathol Pharmacol. 2013;26(3):795-800. 
29. Heyman M, Darmon N, Dupont C, et al. Mononuclear cells from infants allergic to cow's milk secrete tumor necrosis factor alpha, altering intestinal function. Gastroenterology. 1994;106(6):1514-1523.

30. Miceli Sopo S, Iacono I, Greco M, Monti G. Clinical management of food protein-induced enterocolitis syndrome. Curr Opin Allergy Clin Immunol. 2014;14(3):240-245.

31. Caubet JC, Nowak-Wegrzyn A. Current understanding of the immune mechanisms of food protein-induced enterocolitis syndrome. Expert Rev Clin Immunol. 2011;7(3):317-327.

32. Caubet JC, Bencharitiwong R, Ross A, Sampson HA, Berin MC, Nowak-Wegrzyn A. Humoral and cellular responses to casein in patients with food protein-induced enterocolitis to cow's milk. J Allergy Clin Immunol. 2017;139(2):572-583.

33. Mori F, Barni S, Cianferoni A, Pucci N, de Martino M, Novembre E. Cytokine expression in CD3+ cells in an infant with food proteininduced enterocolitis syndrome (FPIES): case report. Clin. Dev. Immunol. 2009;2009:679381.

34. McDonald PJ, Goldblum MR, Van Sickle GJ, Powell GK. Food proteininduced enterocolitis: altered antibody response to ingested antigen. Pediatr Res. 1984;18(8):751-755

35. Fontaine JL, Navarro J. Small intestinal biopsy in cows milk protein allergy in infancy. Arch Dis Child. 1975;50(5):357-362.

36. Chung HL, Hwang JB, Kwon YD, Park M, Shin W, Park J. Deposition of eosinophil-granule major basic protein and expression of intercellular adhesion molecule-1 and vascular cell adhesion molecule- 1 in the mucosa of the small intestine in infants with cow's milk-sensitive enteropathy. J Allergy Clin Immunol. 1999;103(6):1195-1201.

37. Banzato C, Piacentini GL, Comberiati P, Mazzei F, Boner AL, Peroni DG. Unusual shift from IgE-mediated milk allergy to food proteininduced enterocolitis syndrome. Eur Ann Allergy Clin Immunol. 2013;45(6):209-211.

38. Konstantinou GN, Bencharitiwong R, Grishin A, et al. The role of caseinspecific IgA and TGF- $\beta$ in children with food protein-induced enterocolitis syndrome to milk. Pediatr Allergy Immunol. 2014;25(7):651-656.

39. Levy Y, Danon YL. Food protein-induced enterocolitis syndrome-not only due to cow's milk and soy. Pediatr Allergy Immunol. 2003;14(4):325-329.

40. Remon Z, Alonso LE, Martin F, Martinez M. Food protein-induced enterocolitis syndrome caused by fish. Allergol Immunopathol (Madr). 2005;33(6):312-316.

41. Hsu P, Mehr S. Egg: a frequent trigger of food protein-induced enterocolitis syndrome. J Allergy Clin Immunol. 2013;131(1):241-242.

42. Fernandes BN, Boyle RJ, Gore C, Simpson A, Custovic A. Food protein-induced enterocolitis syndrome can occur in adults. J Allergy Clin Immunol. 2012;130(5):1199-1200.

43. Borchers SD, Li BU, Friedman RA, McClung HJ. Rice-induced anaphylactoid reaction. J Pediatr Gastroenterol Nutr. 1992;15(3):321-327.

44. Cavataio F, Carroccio A, Montalto G, Iancono G. Isolated rice intolerance: clinical and immunologic characteristics in four infants. J Pediatr. 1996;128(4):558-560.

45. Vandenplas Y, Edelman R, Sacré L. Chicken-induced anaphylactoid reaction and colitis. J Pediatr Gastroenterol Nutr. 1994;19(2):240-241.

46. Arik Yilmaz E, Cavkaytar O, Uysal Soyer O, Sackesen C. Egg yolk: an unusual trigger of food protein-induced enterocolitis syndrome. Pediatr Allergy Immunol. 2014;25(3):296-297.

47. Caubet JC, Nowak-Wegrzyn A. Food protein-induced enterocolitis to hen's egg. J Allergy Clin Immunol. 2011;128(6):1386-1388.

48. Caubet JC, Szajewska H, Shamir R, Nowak-Węgrzyn A. Non IgEmediated gastrointestinal food allergies in children. Pediatr Allergy Immunol. 2017;28(1):6-17.

49. Australian Institute of Health and Welfare Canberra2010. Australian National Infant Feeding Survey. Indicator results. 2011. Available from: http://www.aihw.gov.au/WorkArea/DownloadAsset. aspx?id=10737420925. Accessed May 15, 2017.

50. Grummer-Strawn LM, Scanlon KS, Fein SB. Infant feeding and feeding transitions during the first year of life. Pediatrics. 2008;122 (Suppl 2): S36-S42.
51. Hwang JB, Kang KJ, Kang YN, Kim AS. Probiotic gastrointestinal allergic reaction caused by Saccharomyces boulardii. Ann Allergy Asthma Immunol. 2009;103(1):87-88.

52. Miceli Sopo S, Monaco S, Badina L, et al. Food protein-induced enterocolitis syndrome caused by fish and/or shellfish in Italy. Pediatr Allergy Immunol. 2015;26(8):731-736.

53. Leonard SA, Nowak-Wegrzyn A. Clinical diagnosis and management of food protein-induced enterocolitis syndrome. Curr Opin Pediatr. 2012;24(6):739-745.

54. Powell, GK. Food protein-induced enterocolitis of infancy: differential diagnosis and management. Compr Ther. 1986;12(2):28-37.

55. Nowak-Wegrzyn A. Food protein-induced enterocolitis syndrome and allergic proctocolitis. Allergy Asthma Proc. 2015;36(3): $172-184$.

56. Boyce J, Assa'ad A, Burks AW, et al. Guidelines for the diagnosis and management of food allergy in the United States: summary of the NIAID-Sponsored Expert Panel Report. J Allergy Clin Immunol. 2010;126(6):1105-1118.

57. Järvinen K, Nowak-Wegrzyn A. A. Food protein-induced enterocolitis syndrome: current management strategies and review of the literature. J Allergy Clin Immunol Pract. 2013;1(4):317-322.

58. Muraro A, Werfel T, Hoffmann-Sommergruber K, et al. EAACI food allergy and anaphylaxis guidelines: diagnosis and management of food allergy. Allergy. 2014;69(8):1008-1025.

59. Wang J, Fiocchi A. Unmet needs in food protein-induced enterocolitis syndrome. Curr Opin Allergy Clin Immunol. 2014;14(3): 206-207.

60. Barasche J, Stollar F, Bermann M, Caubet JC. Severely altered-consciousness status and profuse vomiting in infants: food protein-induced enterocolitis syndrome (FPIES) a challenging diagnosis. Pediatr Emerg Care. Epub 2016 Oct 6.

61. Jayasooriya S, Fox AT, Murch SH. Do not laparotomize foodprotein-induced enterocolitis syndrome. Pediatr Emerg Care. 2007;23(3):173-175.

62. Holbrook T, Keet CA, Frischmeyer-Guerrerio PA, Wood RA. Use of ondansetron for food protein-induced enterocolitis syndrome. JAllergy Clin Immunol. 2013;132(5):1219-1220.

63. Leonard SA, Nowak-Wegrzyn A. Food protein-induced enterocolitis syndrome: an update on natural history and review of managment. Ann Allergy Asthma Immunol. 2011;107(2):95-101.

64. Berin MC. Immunopathophysiology of food protein-induced enterocolitis syndrome. J Allergy Clin Immunol. 2016;135(5):1108-1113.

65. Miceli Sopo S, Battista A, Greco M, Monaco S. Ondansetron for food protein-induced enterocolitis syndrome. Int Arch Allergy Immunol. 2014;164(2):137-139.

66. Mane SK, Hollister ME, Bahna SL. Food protein-induced enterocolitis syndrome to trivial oral mucosal contact. Eur J Pediatr. 2014;173(12):1545-1547.

67. Khanna N, Patel K. FPIES: reviewing the management of food protein-induced enterocolitis syndrome. Case Rep Pediatr. 2016;2016: 1621827.

68. Kaya A, Toyran M, Civelek E, Mısırlıoglu ED, Kırsaçlıoglu CT, Kocabaş CN. Food protein-induced enterocolitis syndrome in two exclusively breastfed infants. Pediatr Allergy Immunol. 2016;27(7): 749-750.

69. Niggemann B, Binder C, Dupont C, Hadji S, Arvola T, Isolauri E. Prospective, controlled, multicenter study on the effect of an aminoacid-based formula in infants with cow's milk allergy/intolerance and atopic dermatitis. Pediatr Allergy Immunol. 2001;12(2):78-82.

70. Hill DJ, Murch SH, Rafferty K, Wallis P, Green CJ. The efficacy of amino acid-based formulas in relieving the symptoms of cow's milk allergy: a systematic review. Clin Exp Allergy. 2007;37(6): 808-822.

71. Fiocchi A, Brozek J, Schunemann H, et al. World Allergy Organization (WAO) Diagnosis and Rationale for Action against Cow's Milk Allergy (DRACMA) guidelines. Pediatr Allergy Immunol. 2010;21 (Suppl 21): $1-125$. 
72. Miceli Sopo S, Buonsenso D, Monaco S, Crocco S, Longo G, Calvani M. Food protein-induced enterocolitis syndrome (FPIES) and well cooked foods: a working hypothesis. Allergol Immunopathol (Madr). 2013;41(5):346-348.

73. Nowak-Węgrzyn A, Chehade M, Groetch ME, Spergel JM, et al. International consensus guidelines for the diagnosis and management of food protein-induced enterocolitis syndrome: Executive summaryWorkgroup Report of the Adverse Reactions to Foods Committee, American Academy of Allergy, Asthma \& Immunology. J Allergy Clin Immunol. 2017;139(4):1111-1126.

74. Miceli Sopo S, Greco M, Monaco S, Tripodi S, Calvani M. Food proteininduced enterocolitis syndrome, from practice to theory. Expert Rev Clin Immunol. 2013;9(8):707-715.
75. Serafini S, Bergmann MM, Nowak-Węgrzyn A, Eigenmann PA, Caubet JC. A case of food protein-induced enterocolitis syndrome to mushrooms challenging currently used diagnostic criteria. J Allergy Clin Immunol Pract. 2015;3(1):135-137.

76. Barasche J, Stollar F, Bergmann MM, Caubet JC. Severely alteredconsciousness status and profuse vomiting in infants: Food ProteinInduced Enterocolitis Syndrome (FPIES) a challenging diagnosis. Pediatr Emerg Care. Epub 2016 Oct 6.

77. Nowak-Wegrzyn A, Chehade M, Groetch ME, . International consensus guidelines for diagnosis and management of food protein-induced enterocolitis syndrome: Executive summary-Workgroup Report of the Adverse Reactions to Foods Committee, American Academy of Allergy, Asthma \& Immunology. J Allergy Clin Immunol. Epub 2017 Feb 4.
Journal of Asthma and Allergy

\section{Publish your work in this journal}

The Journal of Asthma and Allergy is an international, peer-reviewed open access journal publishing original research, reports, editorials and commentaries on the following topics: Asthma; Pulmonary physiology; Asthma related clinical health; Clinical immunology and the immunological basis of disease; Pharmacological interventions and

\section{Dovepress}

new therapies. This journal is included in PubMed. The manuscript management system is completely online and includes a very quick and fair peer-review system, which is all easy to use. Visit http://www. dovepress.com/testimonials.php to read real quotes from published authors. 